\title{
Quadro eritrocitário e índice de Haden para avaliação de anemia em vacas lactantes na região de Imperatriz-MA
}

Joelsy Dias Costa ${ }^{1}$, Manoel de Oliveira Dantas ${ }^{2^{*}}$, Raquel Leite dos Santos ${ }^{3}$, Thays de Paula Menezes Pereira ${ }^{4}$, Décio Romão dos Santos Neto ${ }^{5}$, Vannessa Julliana Coelho Santos de Melo ${ }^{6}$, Murilo Alves Barros ${ }^{7}$, Nayra Juliana Lima Vale ${ }^{8}$, Dennis Leite dos Santos ${ }^{9}$, Paulo Vitor Silva de Carvalho ${ }^{9}$

${ }^{I}$ Bolsista PIBIC/UEMA - Clivet, joelsy_dias@ hotmail.com

${ }^{2}$ Professor PhD Orientador UEMA/CESI, cardioequino@hotmail.com

${ }^{3}$ Pesquisadora voluntáriaCESI/UEMA, kel_leite7@hotmail.com

${ }^{4}$ Pesquisadora voluntária CESI/UEMA, thaysmenezees@gmail.com

${ }^{5}$ Pesquisador voluntário CESI/UEMA, decioneto7@live.com

${ }^{6}$ Bolsista PIVIC CESI/UEMA, ju_coelho_@hotmail.com

${ }^{7}$ Professor Estatística Experimental, murilomp@yahoo.com.br

${ }^{8}$ Pesquisadora voluntária PIVIC/UEMA, pra.nayara@hotmail.com

${ }^{9}$ Mestrando em Ciência Animal UEMA, dennisleite@outlook.com.br

RESUMO. A cidade de Imperatriz possui grande importância na bacia leiteira do Maranhão, sendo esta responsável por metade da produção de todo o Estado. Diante disso, buscou-se a melhoria da sanidade dos rebanhos a fim de aumentar a produção, bem como melhorar a qualidade do produto produzido pesquisando-se neste trabalho o quadro eritrocitário e valores do índice de Haden de vacas em lactação para avaliação de quadro anêmico dos rebanhos inseridos na região de Imperatriz. Utilizou-se 145 animais de rebanhos leiteiros previamente cadastrados, os quais foram sangrados na veia jugular ou coccídea, previamente desinfetada com iodo a $10 \%$, e mediante agulhas hipodérmicas 40x12 eram colhidos $5 \mathrm{ml}$ de sangue em seringas descartáveis e condicionados em frascos com EDTA, sendo as amostras conduzidas em caixa térmica ao Laboratório de Biologia Animal da Universidade Estadual do Maranhão. As análises foram processadas pelos meios convencionais da hematologia clínica, determinando-se a contagem total das hemácias $\left(10^{6}\right)$, a dosagem da hemoglobina $(\mathrm{g} / \mathrm{dl})$ o volume globular $(\%)$ e a série hematimétrica absoluta, VGM (Volume Globular Médio), HGM (Hemoglobina Globular Média) e a CHGM (Concentração Hemoglobina Globular Média) de cada hemácia com intuito de classificar a série hematimétrica absoluta, assim como também avaliação do índice de Haden. Mediante os resultados obtidos foram observados valores, para hemácia $\mathrm{F}=220.1971 * *$ e hematócrito $\mathrm{F}=1032.3724 * *$ que mesmo abaixo da média fisiológica para a espécie, registra condicionamento orgânico do animal para compensar os déficits existentes com a hemoglobina que se encontra abaixo dos níveis normais. No entanto, isso ocasionou um aumento na concentração de hemoglobina globular média, F $=7.9386^{* *}$ como resposta fisiológica para melhor transporte de $\mathrm{O}_{2}$, como forma de compensação do organismo animal devido à baixa quantidade do número de hemácias circulantes e produção de leite registrada. Na avaliação do índice de Haden constatou-se um quadro anêmico - anemia microcítica hipocrômica, confirmando os resultados do eritrograma.

Palavras chave: Eritrograma, quadro anêmico, hematologia.

\section{Study of table erythrocyte and Haden Index for evaluation of anemia in lactating cows of Imperatriz - Maranhão region}

ABSTRACT. The Imperatriz city has great importance in the dairy region of Maranhão, which is responsible for half of the production throughout the state. Therefore, we sought the improvement of the livestock's health in order to increase production and enhance the 
quality of the product produced by searching in this work the erythrocyte framework and values of Haden index for evaluation of the anemic framework of the dairy cows in the region. It was used 145 dairy cattle animals previously registered which were weekly bled in the jugular vein or Coccidial, previously disinfected with iodine $10 \%$ by $40 \times 12$ hypodermic needles, it were taken samples of $5 \mathrm{ml}$ of blood in disposables syringes and conditioned in flasks containing EDTA, and the samples conducted in thermal box to the Animal Biology Laboratory at the State University of Maranhão. Analyses were processed by means of conventional clinical hematology, determining the total count of red blood cells $\left(10^{6}\right)$, the dosage of hemoglobin $(\mathrm{g} / \mathrm{dl})$ the packed cell volume $(\%)$ and the absolute hematimetric serial, MCV (mean corpuscular volume), MCH (Mean Corpuscular Hemoglobin) and the CHGM (Concentration Mean Corpuscular Hemoglobin) of each red blood cell in order to classification the absolute hematimetric series, as well as evaluation of Haden index. From the results obtained values were observed for red blood cell $\mathrm{F}=220.1971 * *$ and hematocrit $\mathrm{F}=1032.3724 * *$ even though it is below of the physiological average for the species, it is recorded organic conditioning to offset existing deficits with hemoglobin that is noticed below of the normal levels, taking an increase in mean corpuscular hemoglobin concentration, and $\mathrm{F}=$ $7.9386 * *$ as physiological response to a better $\mathrm{O}_{2}$ transport as ways of the animal organism compensation due to the low count of the number of circulating red cells and production of milk recorded. The Haden índex examination was found out an anemic frame - microcitichypochromic anemia, confirming the erythrogram results.

Keywords: Erythrogram, anemic table, hematology

\section{Introdução}

O município de Imperatriz é considerado um grande produtor dentro da bacia leiteira do Maranhão, sendo responsável por metade da produção de leite em todo Estado (Silva et al., 2012a, Silva et al., 2012b). Com isso, há necessidade de que os rebanhos sejam cada vez mais saudáveis. Para isso, tem-se como aliado o uso de exames complementares como o eritrograma, pois além de sua praticidade, também apresenta baixo custo e nos permite uma avaliação e classificação de um possível quadro anêmico existente no rebanho.

Segundo Borges (2008), os estudo dos componentes do sangue é tido como uma ferramenta fundamental, sendo que através dele pode-se fazer avaliação do estado nutricional e detecção de algumas alterações patológicas teciduais e metabólicas em diferentes situações da vida do animal. Por meio do eritrograma é possível avaliar as células vermelhas do sangue. Sendo este, composto pela contagem dos valores de hemácias, hemoglobina, hematócrito, além dos índices hematimétricos - VGM (Volume Globular Médio), HGM (Hemoglobina Globular Media), CHGM (Concentração de Hemoglobina Globular Médio) (Lopes et al., 2007).

As funções do sangue estão relacionadas ao transporte de nutrientes, oxigênio, hormônios, dióxido de carbono e retirada de produtos do metabolismo celular. $\mathrm{O}$ sangue também possui funções adicionais quanto sua participação na manutenção dos equilíbrios hídricos e do $\mathrm{pH}$ no corpo (Reece, 2008).

A avaliação hematológica tem sido fundamental na obtenção de diagnósticos e prognósticos de enfermidades que prejudicam a sanidade dos rebanhos bovinos, impactando assim na redução da produção de leite e carne (Galindo, 2011). O sangue está diretamente ligado à produção de leite, sendo responsável pelo transporte de hormônios que controlam o desenvolvimento do úbere, a síntese de leite e a regeneração de células secretoras entre as lactações. Além de que, para uma vaca produzir 1 $\mathrm{kg}$ de leite é necessário que cerca de 400 a 500 litros de sangue passem pelo úbere (Wattiaux, 1995).

Outro fator importante da avaliação eritrocitária é a possibilidade de se diagnosticar possíveis quadros anêmicos. Birchard \& Sherding (2008) afirmam que a anemia pode ser caracterizada tanto pela redução do volume globular quanto pelo número de hemácias ou diminuição da concentração de hemoglobina. A anemia é uma anormalidade hematológica de constante ocorrência na rotina clínica, sendo esta considerada como consequência de outras patologias e não considerada como uma doença 
primária. Com isso, as causas para a ocorrência de uma anemia podem ser destacadas em três categorias: hemorragia, hemólise e menor produção de eritrócitos.

A anemia por perda de sangue ocasionada pela ocorrência de hemorragia rápida leva a uma diminuição da concentração de células vermelhas, podendo esta ser corrigida pelo organismo em pouco tempo. $\mathrm{Na}$ hemorragia crônica há dificuldade na absorção de ferro no intestino para a formação de hemoglobina. Em consequência, as hemácias produzidas são menores que as normais e contém menor quantidade de hemoglobina originando a anemia microcítica hipocrômica (Guyton \& Hall, 2006). As anemias por hipofunção da medula óssea são caracterizadas pela redução na produção de eritrócitos. Para que ocorra a síntese de DNA são necessários ácido fólicos e vitamina $\mathrm{B}_{12} \mathrm{e}$, sua deficiência provoca diminuição do número de eritrócitos pela redução de mitoses eritróides. A queda na produção de eritrócitos é considerada a principal causa de anemia nas doenças crônicas, tendo como fatores predisponentes: toxemia por abscedação ou uremia, falta de ferro e nutrição inadequada (Fraser et al., 1996). Segundo Campos et al. (2008) as alterações hematológicas relacionadas aos animais em lactação podem variar entre rebanhos e, os baixos parâmetros eritrocitários durante este período podem estar relacionados com o nível de produção leiteira, com a nutrição do animal e com o aumento do volume plasmático. Em geral, os animais de maior produção possuem valores eritrocitários menores em relação aos animais de menor produção.

Diante disto, o presente trabalho tem por objetivo determinar por meio de avaliação hematológica os valores médios dos parâmetros do perfil eritrocitário e posterior classificação de quadro anêmico, através do Índice de Haden, de vacas em lactação no município de Imperatriz Maranhão.

\section{Justificativa}

Para Lorenzi (1992), o sangue é um tecido fluido formado por uma porção celular, onde esta circula em suspensão em um meio líquido denominado plasma. Os componentes celulares do sangue podem ser separados por centrifugação, sendo estes divididos em duas partes, uma líquida denominada plasma que possui peso menor que as células e, portanto se apresenta na parte superior do tubo de centrífuga (Cunningham, 2011). A parte celular é composta pelos eritrócitos (células vermelhas do sangue), leucócitos (células brancas do sangue) e plaquetas também conhecidas como trombócitos (Lopes et al., 2007). As análises sanguíneas são utilizadas como apoio para a obtenção de diagnósticos clínicos, tendo em vista, que o peso corporal de um animal é composto por $8 \%$ de sangue. A hematologia veterinária é importante na identificação de doenças de forma precoce. Alterações hematológicas podem estar associadas a doenças na medula óssea, no tecido sanguíneo, doenças infecciosas, doenças imunomediadas e neoplasias. O conhecimento e o diagnóstico dessas doenças são de fundamental importância para um correto tratamento.

\section{Eritropoese}

A eritropoese é a produção dos eritrócitos. Esta produção, durante a vida fetal, ocorre no fígado, baço e medula óssea. Por outro lado, durante a vida pós-fetal até a vida adulta, a eritropoese se restringe quase que exclusivamente à medula óssea (Reece, 2008). A eritropoese é regulada pela eritropoetina que regula a produção normal e a estimula quando há demanda, principalmente nos casos de hipóxia tecidual (Fraser et al., 1996). A diminuição da quantidade de oxigênio transportada pelo sangue até os tecidos leva à secreção de eritropoetina, onde esta atua na medula óssea (Lorenzi, 1992). Segundo Dukes et al. (2006), na medula óssea, a eritropoietina (EPO) estimula as células troncos comprometidas, incluindo os rubriblastos, os prórubrícitos e rubrícitos jovens, visando aumentar a sua atividade mitótica para a produção e liberação mais rápida de reticulócitos e eritrócitos maduros. Durante a eritropoese ocorrem no mínimo quatro mitoses até a formação do eritrócito. A primeira ocorre na fase de rubriblasto, a segunda no estágio de pró-rubrícito e as posteriores no estágio de rubrícito basofílico. Com isso, o rubrícito basofílico matura-se em rubrícito policromatofílico, que se transformará em metarrubrícito, reticulócitos e eritrócitos (Figura 1) (Lopes et al., 2007).

\section{Eritrócitos}

Os eritrócitos, nos animais adultos, são constituídos por 62 a $75 \%$ de água e aproximadamente $35 \%$ de sólidos. Destes, a hemoglobina corresponde à maior parte cerca de $95 \%$. O tempo de vida dos eritrócitos varia de 
acordo com a espécie, nos bovinos adultos varia de 125 a 150 dias (Dukes et al., 2006). Segundo Guyton \& Hall (2006), Hoffbr\& \& Moss (2013) o transporte de oxigênio dos pulmões para os tecidos é feito pela hemoglobina contida nas hemácias circulantes. Com isso, ocorre também a retirada de $\mathrm{CO}_{2}$ para ser eliminado, na atmosfera, sendo este produto do metabolismo corporal. A destruição eritrocitária ocorre por meio da fagocitose por macrófagos e a lise intravascular, liberando hemoglobina. A ação dos macrófagos dá-se com o reconhecimento de anticorpos $\operatorname{IgG}$ aderidos a antígenos de membrana nos eritrócitos danificados e/ou envelhecidos. Em conjunto com a destruição eritrocitária, ocorre a liberação de células jovens, também conhecidas como reticulócitos, da medula óssea para o sangue periférico (Lopes et al., 2007).

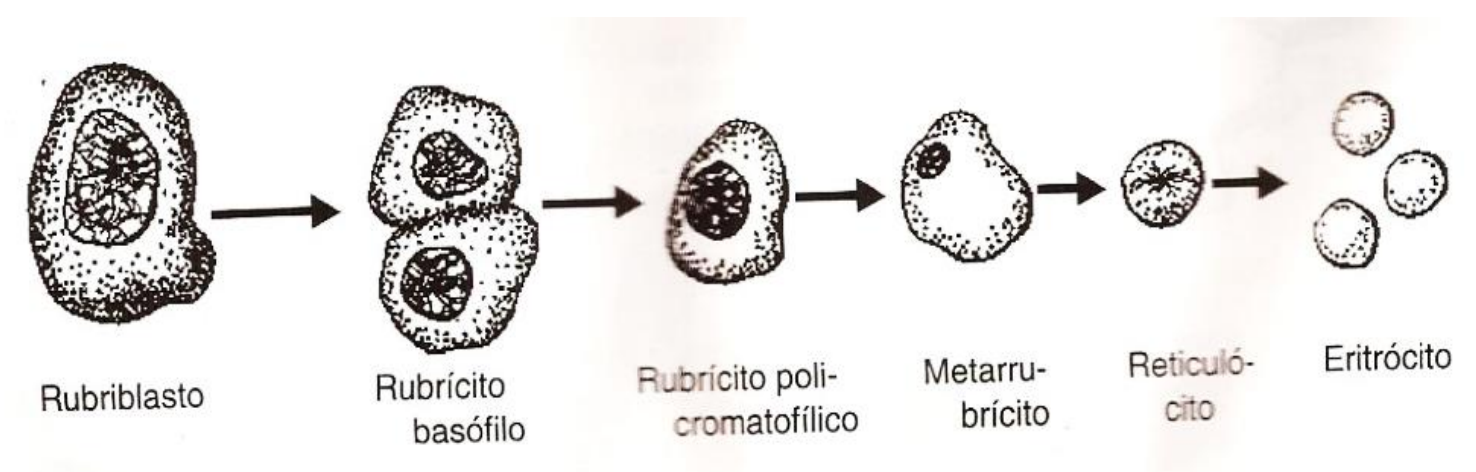

Figura1. Estágios do desenvolvimento do eritrócito. Fonte Reece (2006)

\section{Hemoglobina}

Para Lopes et al. (2007), a hemoglobina é considerada uma proteína conjugada, sendo formada de $96 \%$ de proteínas (globulinas) e por um grupo prostético de coloração vermelho chamado heme (4\%), o qual é formado por ferro e grupamentos porfirínicos. A hemoglobina presente nos eritrócitos é responsável pela cor vermelha do sangue. Esta é influenciada pelo grau de saturação do oxigênio, que quanto maior, mais brilhante a coloração vermelha. A cor do plasma sanguíneo é resultante da bilirrubina, produto da degradação da hemoglobina. Em vacas, tem coloração escura, devida uma maior concentração de bilirrubina (Reece, 2008).

\section{Índices eritrocitários}

Os índices eritrocitários são obtidos a partir dos resultados do número de eritrócitos, volume globular e concentração de hemoglobina. Os índices indicados são: VGM (Volume Globular Médio), HGM (Hemoglobina Globular Médio) e CHGM (Concentração de Hemoglobina Globular Médio) (Dukes et al., 2006). Os índices hematimétricos são utilizados para o diagnóstico de diferentes anemias. O VGM expressa o tamanho médio da célula em micrômetros cúbicos. Por outro lado, o HGM fornece o peso médio da hemoglobina presente na hemácia. $\mathrm{O}$ CHGM demonstra o percentual médio que a hemoglobina ocupa dentro do volume globular médio (Dukes et al., 2006).

\section{Hematócrito ou Volume Globular (\%)}

$\mathrm{O}$ hematócrito ou volume globular corresponde à percentagem de eritrócitos presentes no sangue. Este é considerado um exame de alta praticidade e baixo custo, tornando-o cada vez mais utilizado para análise da série vermelha, por isso muito útil no auxílio de diagnósticos e obtenção de algumas informações importantes como: a coloração do plasma, capa leucocitária, e a presença de microfilárias e Tripanossoma spp (Lopes et al., 2007). Além disso, o hematócrito afeta diretamente a viscosidade sanguínea (Cunningham, 2011) e por meio deste pode-se avaliar um possível quadro anêmico e a necessidade de realização de transfusão sanguínea. Para isso, existem valores considerados indicadores da necessidade de transfusão, os quais variam de acordo com a espécie animal. Para bovinos o indicador considerado é o valor de hematócrito menor ou igual a 14\%. Segundo Guyton \& Hall (2006), o hematócrito é obtido por meio da centrifugação do sangue, onde ocorre a divisão dos constituintes sanguíneos, de acordo com seu peso específico relativo. Assim, a parte composta pelos eritrócitos se encontra na porção inferior, ao passo que leucócitos e plaquetas localizam-se 
na porção medial e o plasma ocupando porção superior. Com o intuito de aumentar a precisão do valor de hematócrito e uniformizar, Reece \& Penteado Júnior (1996) descrevem o microhematócrito, sendo o mesmo obtido utilizando-se micro centrífuga para centrifugação do sangue contido em tubos capilares, durante cinco minutos a 11.000 rotações por minuto. Obtendo assim, a mesma apresentação descrita por (Guyton \& Hall, 2006) e a proporção da coluna de sangue ocupada pelos eritrócitos é obtida através de régua especial.

\section{Anemias}

Birchard \& Sherding (2008) afirmam que a anemia é caracterizada pela redução do volume globular, número de hemácias ou na diminuição da concentração de hemoglobina. A anemia é uma anormalidade hematológica de constante ocorrência na rotina clínica, sendo esta considerada como consequência de outras patologias e não considerada como uma doença primária. Com isso, as causas para a ocorrência de uma anemia podem ser destacadas em três categorias: hemorragia, hemólise e menor produção de eritrócitos. A anemia por perda de sangue ocasionada pela ocorrência de hemorragia rápida leva, a uma diminuição da concentração de células vermelhas, podendo esta ser corrigida pelo organismo em pouco tempo. Na hemorragia crônica há dificuldade na absorção de ferro no intestino para a formação de hemoglobina. Em consequência, as hemácias produzidas são menores que as normais e contém menor quantidade de hemoglobina originando a anemia microcítica hipocrômica (Guyton \& Hall, 2006). Anemias hemolíticas são associadas à hemólise de hemácias, e estas podem ocorrer intra ou extra vascular. No entanto, nos bovinos há uma maior ocorrência de hemólise intravascular oriunda de processos patológicos provocados por hemoparasitos (Rebhun \& Oliveira, 2000). As anemias por hipofunção da medula óssea são caracterizadas pela redução na produção de eritrócitos. Para que ocorra a síntese de DNA, são necessários ácido fólico, cobalto e vitamina $\mathrm{B} 12 \mathrm{e}$, sua deficiência provoca diminuição do número de eritrócitos pela redução de mitoses eritróides. A queda na produção de eritrócitos é considerada a principal causa de anemia nas doenças crônicas, tendo como fatores predisponentes: toxemia por abscedação ou uremia, falta de ferro e nutrição inadequada (Fraser et al., 1996).

\section{Classificação morfológica das anemias}

A classificação morfológica das anemias pode ser obtida por meio da avaliação dos índices eritrocitários: Volume Globular Médio (VGM) e Concentração de Hemoglobina Globular Média (CHGM). Com relação ao VGM, classificam-se as anemias em normocítica, macrocítica e microcítica. Por outro lado, com relação à concentração de hemoglobina as anemias são classificadas em normocrômica e hipocrômica (Lopes et al., 2007). A anemia macrocítica normocrômica é caracterizada pela deficiência de cobalto ou de pastos rico em molibdênio. Por sua vez, a anemia macrocítica hipocrômica é observada em casos de perda aguda de sangue e hemólise aguda. A anemia normocítica normocrômica ocorre pela depressão da eritropoese e por fim a anemia microcítica hipocrômicaé resultante da deficiência de ferro ou dificuldade na utilização do ferro na produção de hemoglobina (Lopes et al., 2007).

\section{Efeitos da anemia sobre o sistema circulatório}

A concentração das hemácias é responsável pela viscosidade do sangue. Em casos de anemia a viscosidade sanguínea diminui e assim reduz a resistência do fluxo de sangue nos vasos periféricos, ocasionando um aumento do volume sanguíneo no organismo e consequentemente do débito cardíaco (Guyton \& Hall, 2006). Intolerância ao exercício é um dos efeitos causados pela anemia. Nos animais ao se exercitarem, há uma maior exigência de oxigênio por parte dos tecidos, no entanto, o coração destes animais está incapaz de suprir essa exigência. Com isso, ocorre hipóxia tecidual extrema levando ao desenvolvimento de insuficiência cardíaca aguda (Guyton \& Hall, 2006).

\section{Policitemia}

Na policitemia, há um aumento no número de eritrócitos circulantes. Esta se divide em policitemia relativa. Há um aumento de eritrócitos e diminuição do volume plasmático e policitemia absoluta com aumento das células vermelhas sem a redução do volume plasmático (Guyton \& Hall, 2006). A policitemia relativa é geralmente decorrente de choque e desidratação nos animais que são tratados com diurético ou medicação para cardiopatas. Por outro lado, a policitemia absoluta pode estar associada à hipoxemia ou a tumores, tendo em vista que em 
ambos os casos é elevada a produção de eritropoetina (Guyton \& Hall, 2006).

\section{Efeitos da policitemia sobre o funcionamento do sistema circulatório}

Na policitemia há um aumento na viscosidade do sangue, assim, ocorre uma diminuição do fluxo sanguíneo pelos vasos periféricos. Com isso, o aumento da viscosidade sanguínea diminui a velocidade de retorno do sangue venoso para o coração. Por outro lado, na policitemia, o volume sanguíneo encontra-se aumentado, aumentando assim o retorno venoso (Guyton \& Hall, 2006).

\section{Índices Hematimétricos (Haden)}

Os índices hematimétricos são de grande importância na hematologia clínica, pois o mesmo nos permite um estudo hematológico das anemias, além de nos fornecer dados para diagnóstico, tratamento e possibilitar a classificação morfológica das anemias (Lima et al., 1992). Segundo Haden, os índices hematimétricos são obtidos a partir dos valores da contagem de eritrócitos, dosagem de hemoglobina e valor de hematócrito, estabelecendo assim uma relação entre si (Lima et al., 1992). Os índices de maior importância são: índice volumétrico, o qual expressa o volume médio eritrocitário em relação ao seu valor médio normal; índice colorimétrico que expressa teor de hemoglobina contida em cada eritrócito em relação ao seu teor normal e por fim, o índice de saturação, o qual expressa à concentração média de hemoglobina contida nos eritrócitos por unidade de volume, em relação a sua concentração normal (Lima et al., 1992).

Os valores normais para o índice volumétrico devem oscilar entre 0,9 e 1,1 sendo que valores inferiores ao normal são encontrados nas anemias microcíticas, enquanto que valores superiores são encontrados nas anemias macrocíticas; já os valores para índice colorimétrico oscilam entre 0,9 e 1,1 onde, os valores abaixo são encontrados nas anemias hipocrômicas e valores superiores ao normal são encontrados nas anemias hipercrômicas (Lima et al., 1992). O índice de saturação deve oscilar entre 0,8 e 1,2; valores inferiores são comuns em casos de anemias hipossaturadas e superiores não ocorrem na prática, pois os eritrócitos encontram-se saturados ao máximo de hemoglobina (Lima et al., 1992).

\section{Material e Métodos}

A pesquisa foi desenvolvida em propriedades pertencentes à bacia leiteira da região de Imperatriz - MA, utilizando-se os equipamentos dos projetos Fundeci e edital Universal da Fundação de Amparo à Pesquisa e Desenvolvimento Científico do Maranhão Fapema, ambos já implantados, como também o prévio cadastro dos produtores de leite registrados na Agência de Defesa Agropecuária do Maranhão - AGED/Imperatriz.

Utilizou-se 145 bovinos leiteiros em diferentes fases de lactação que estavam em produção leiteira e em bom estado de saúde orgânica. Os animais foram devidamente identificados, atraves do nome ou numeração, sendo cada animal considerado uma parcela estatística.

Após manejo e identificação do animal (Figura 2), o local de punção era higienizado com substâncias antissépticas e assim puncionada a veia jugular (Figura 3) ou veia coccígea média com agulha descartáveis 40x12 acopladas a seringas descartáveis e assim colhido $5 \mathrm{ml}$ de sangue total, sendo posteriormente acondicionado em tubo de ensaio contendo anticoagulante do tipo EDTA. As amostras eram homogeneizadas e armazenado em caixas térmicas com gelo reciclável e encaminhado ao Laboratório de Biologia Animal do Centro de Estudos Superiores de Imperatriz (CESI/UEMA) para as análises hematológicas propostas (Figura4).

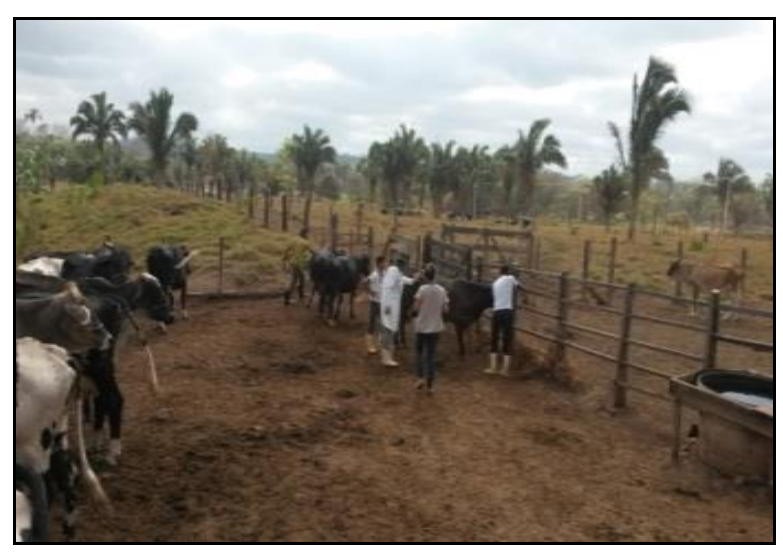

Figura 2. Manejo dos animais nas propriedades. Fonte: Autor (2014).

\section{Métodos de avaliação dos parâmetros do Eritrograma}

Os parâmetros que compõem o eritrograma: contagem de hemácias, dosagem da 
hemoglobina, determinação do hematócrito e a série hematimétrica absoluta (VGM, HGM e CHGM) foram determinados por meio dos princípios básicos que regem a hematologia clínica (Kaneko et al., 2008).

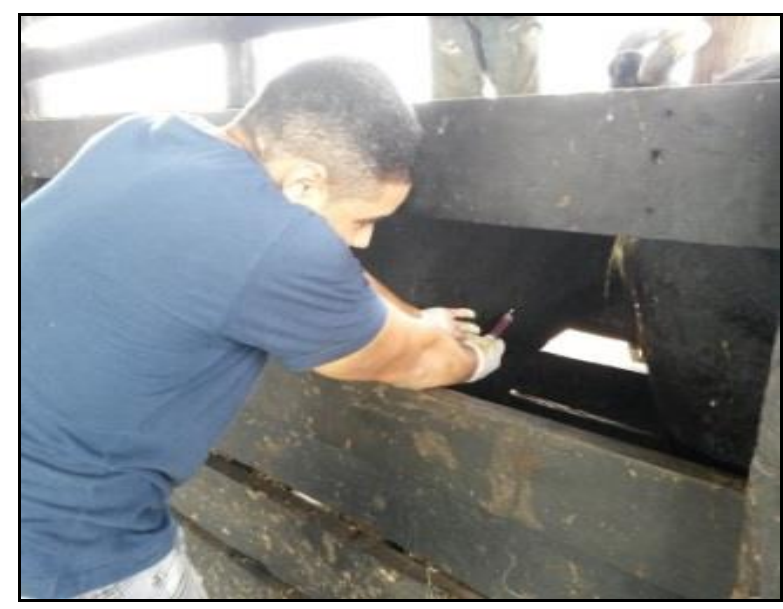

Figura 3. Realização de coleta de sangue pela punção da veia jugular. Fonte: Autor (2014).

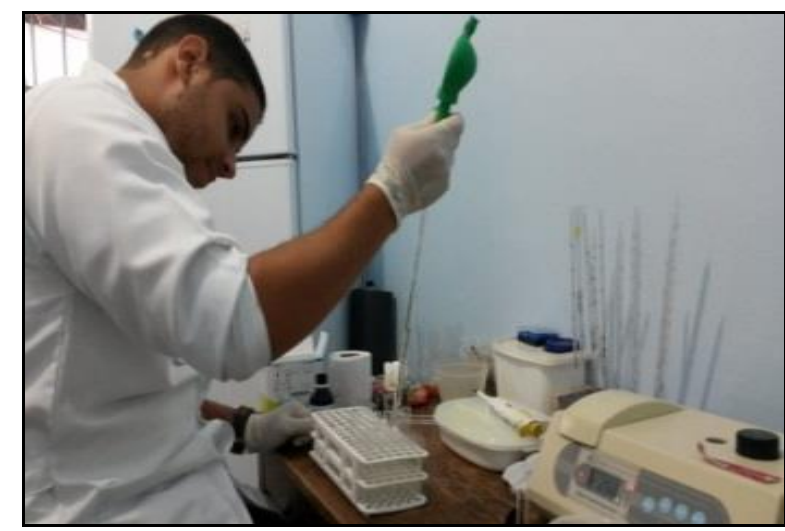

Figura 4. Realização das análises laboratoriais. Fonte: Autor (2014).

\section{Determinação da concentração de hemoglobina}

A concentração de hemoglobina foi determinada segundo metodologia do Laboratório Labtest (Tabela 1). Seguindo o procedimento seguinte:

Tabela 1 - Procedimento para determinação da hemoglobina

\begin{tabular}{l|l}
\hline Itens & Teste \\
\hline Reagente de cor de uso & $5,0 \mathrm{ml}$ \\
Sangue total & $0,02 \mathrm{ml}$ \\
\hline
\end{tabular}

Homegeneização e espera de 5 (cinco) minutos, com posterior determinação da absorbância do teste em $540 \mathrm{~nm}$ ou filtro verde
(520 - 550nm) acertando o zero com água destilada. O valorfoiobtido em $\mathrm{g} / \mathrm{dL}$, sendo utilizada a calibração obtida com o padrão de hemoglobina.

O cálculo realizado utilizou o padrão de hemoglobina

- Fator de calibração $(\mathrm{Fc})=10$ / Padrão

- Hemoglobina $(\mathrm{g} / \mathrm{dL})=\mathrm{Fc} x$ absorbância do teste

\section{Determinação da série hematimétrica absoluta}

Os índices hematimétricos são obtidos a partir dos valores de hematócrito, concentração de hemoglobina e contágem de hemácias, utilizando-se os seguintes cálculos:

- $\mathrm{VGM}=\mathrm{Ht} /$ número de hemácias $\mathrm{x} 10$

- $\mathrm{HGM}=\mathrm{Hg} /$ número de hemácias $\times 10$

- $\mathrm{CHGM}=\mathrm{Hg} / \mathrm{Ht} \times 100$

\section{Determinação do Hematócrito (Volume Globular)}

A determinação do hematócrito foi realizada através da centrifugação do sangue, em tubos capilares onde, por gravidade, os mesmos eram preenchidos $2 / 3$, sendo em seguida centrifugados em microcentrifuga durante cinco minutos a 11.000 rotações por minuto (Figura 5) e em seguida leitura em tabela própria (Figura 6).

Todos os resultados obtidos foram submetidos à análise de variância ANOVA classificando assim, as médias por meio do teste de Tukey e nível de significância.

\section{Resultados e Discussão}

Mediante os resultados obtidos (Tabela 2) a análise de variância revela valores de $\mathrm{F}=$ $220.1971^{* *}$ para hemácias e $\mathrm{F}=$ 1032.3724**para hematócrito altamente significativo e mesmo inferior à média fisiológica considerada para a espécie, registra-se condicionamento orgânico em compensar os déficits existentes com a hemoglobina que se encontra menor do que os níveis normais descritos por Reece \& Penteado Júnior (1996). Com isso, houve um aumento da hemoglobina globular média, $\mathrm{F}=7.9386^{* *}$, que caracteriza uma resposta fisiológica dos animais para melhorar o transporte de Oxigênio, como forma de compensação do organismo animal em virtude da baixa quantidade do número de hemácias circulantes e produção de leite registrada. 


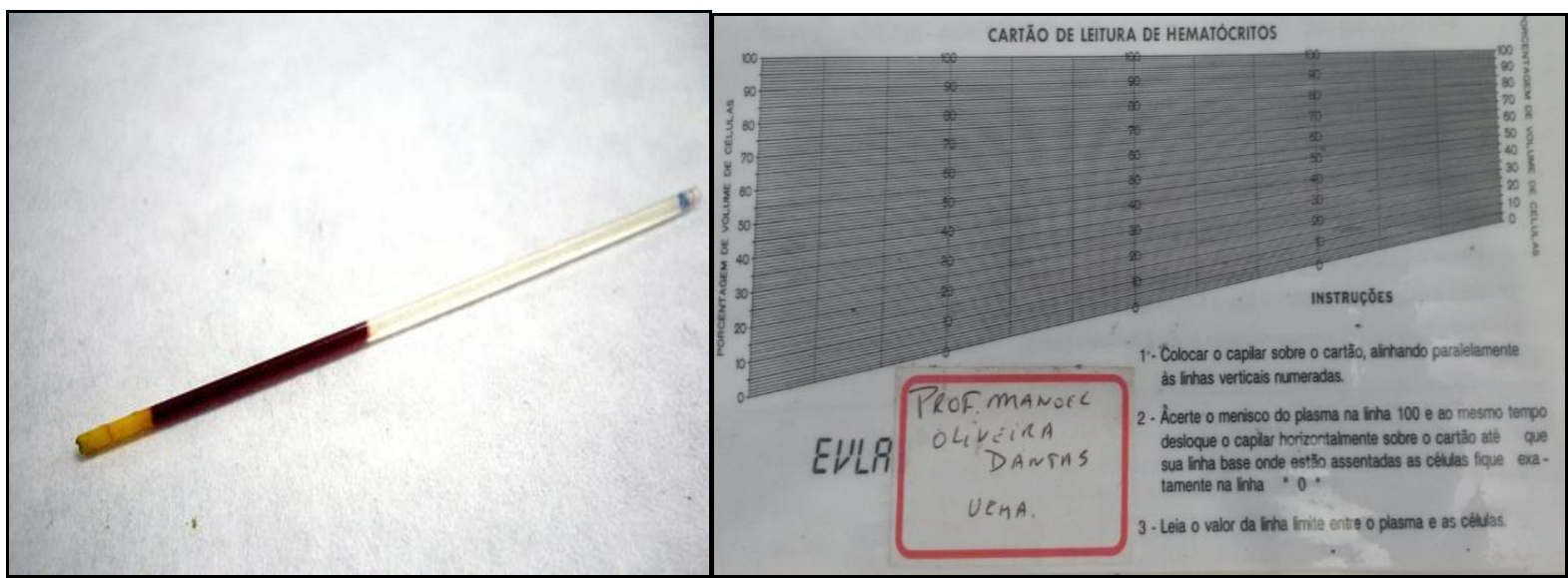

Figura 5. Tubo capilar após centrifugação (A) e tabela especial para leitura de micro-hematócrito (B). Fonte: Autor (2014).

Tabela 2. Demonstrativo dos valores da ANOVA aplicado aos parâmetros do Eritrograma obtidos das vacas leiteiras em produção na região de Imperatriz-MA.

\begin{tabular}{lccccc}
\hline Parâmetros & Valor Médio & DS & CV & SQ & F \\
\hline Hemácias & 6.7171 & 0,9983 & 14,86 & 20.9856220 .1971 & $220.1971^{* * *}$ \\
Hemoglobina & 10,95 & 3,28 & 30,02 & & $1032.3724^{* *}$ \\
Hematócrito & 30,94 & 4,26 & 13,78 & 14.2690 & $7.9386^{* *}$ \\
VGM & 45,21 & 3,22 & 7,13 & & 27115.6470 \\
HGM & 15,88 & 4,37 & 27,56 & &
\end{tabular}

VGM =Volume Globular Médio, HGM = Hemoglobina Globular Média, CHGM = Concentração de Hemoglobina Globular Média, DS = Desvio Padrão, CV= Coeficiente de Variação, $\mathrm{SQ}=$ Soma de Quadrado, ** $(\mathrm{P}<0,01)$

A Análise de correlação de Pearson importância na homeostase revelam todo demonstrada na Tabela 3 observa-se alto índice metabolismo aeróbico das fêmeas em produção, de interação entre hemácia e os parâmetros, uma vez que, os níveis protéicos balanceados Hemoglobina $(\mathrm{P}<0,01)$ Hematócrito $(\mathrm{P}<0,01)$, registrados nas propriedades visitadas Hemoglobina Globular Média $(\mathrm{P}<0,01)$ e condicionaram esses animais a tais respostas Concentração de Hemoglobina Globular Média hematológicas. $(\mathrm{P}<0,01)$. Parâmetros estes que pela sua

Tabela 3. Demonstrativo da Correlação de Pearson aplicada aos parâmetros que compõem o Eritrograma das vacas leiteiras em produção na região de Imperatriz-MA.

\begin{tabular}{l|c|c|c|c|c|c}
\hline Parâmetros & $\mathrm{He}$ & $\mathrm{Hg}$ & $\mathrm{Ht}$ & $\mathrm{VGM}$ & $\mathrm{HGM}$ & $\mathrm{CHGM}$ \\
\hline Hemácia & & $0,559 * *$ & $0,494 * *$ & & $0,347 * *$ & $0,389 * *$ \\
Hemoglobina & & & $0,587 * *$ & $0,357 * *$ & $0,869 * *$ & $0,879 * *$ \\
Hematócrito & & & $0,246 * *$ & & \\
VGM & & & & $0,468 * *$ & $0,334 *$ & \\
HGM & & & & & $0,987 * *$ & \\
CHGM & & & $0,334 * *$ & & & \\
\hline
\end{tabular}

He = Hemácia, $\mathrm{Hg}=$ Hemoglobina, Ht = Hematócrito VGM = Volume Globular Médio. HGM = Hemoglobina Globular Média, CHGM = Concentração de Hemoglobina Globular Média, $(\mathrm{P}<0,01)$ 
Nossas observações comungam com as citações de Melo et al. (2002) quando afirmam que a variação dos valores hematológicos de um animal a outro da mesma espécie é considerável e depende em parte das características: sexo, nutrição, idade, ciclos diurnos e sexuais bem como formas de estresse, tais como exercício físico, calor e frio, tendo ainda as instalações como fator de conforto ou não para os mesmos

Os resultados estatísticos (Tabela 4) revelaram valor de $\mathrm{F}=66.4611^{* *}$ altamente significativo para o índice volumétrico e índice colorimétrico, inferiores à média preconizada pela hematologia básica e descrita por Lima et al. (1992), confirmando uma anemia do tipo Microcítica hipocrômica, caracterizada por deficiência de ferro (Duncan \& Prasse, 1982, Núñez \& Bouda, 2007), o que provavelmente está relacionada aos altos índices de produção dos animais e a algumas falhas na suplementação alimentar em proporcionalidade a sua produtividade.

Tabela 4. Demonstrativo da Análise Estatística Descritiva, dos Índices Volumétrico, Colorimétrico e Saturação de oxigênio do Eritrograma obtido das vacas leiteiras analisadas na região de Imperatriz Maranhão.

\begin{tabular}{lccc}
\hline Itens & $\begin{array}{c}\text { Valor } \\
\text { Médio }\end{array}$ & $\begin{array}{c}\text { Soma do } \\
\text { Quadrado }\end{array}$ & $\begin{array}{c}\text { Valor F } \\
\text { Significância }\end{array}$ \\
\hline IV & 0,61 & 22.225 & $66.4611^{* *}$ \\
IC & 0,65 & & \\
IS & 1,11 & & \\
\hline
\end{tabular}

$* *(\mathrm{P}<0,01)$ IV = Índice Volumétrico, IC = Índice Colorimétrico, IS = Índice de Saturação

\section{Conclusão}

Mediante a metodologia utilizada e os parâmetros analisados pode-se concluir que houve alterações hematologicas significativas nos animais avaliados, demonstrando a existência de um quadro de anemia microcítica hipocrômica, provavelmente devido à deficiencia de ferro proveniente de falhas no manejo nutricional destes animais. O índice Volumétrico de Haden revela oscilações decorrentes do quadro anêmico registrado.

A utilização de exames práticos e de baixo custo como o Eritrograma e o Índice de Haden, aliados ao exame clínico, são muito importantes para uma boa avaliação da sanidade do rebanho.

\section{Referências bibliográficas}

Birchard, S. J. \& Sherding, R. G. (2008). Manual Saunders: clínica de pequenos animais, São Paulo.

Borges, A. C. (2008). Componentes sanguíneos de bovinos (Bos taurus) da raça Pantaneira em diferentes faixas etárias, criados extensivamente. Veterinária. Universidade Federal de Goiás, Goiânia.

Campos, R., Almeida, L. L., Terra, S. R. \& González, F. H. D. (2008). Parâmetros hematológicos e níveis de cortisol plasmático em vacas leiteiras de alta produção no Sul do Brasil. Brazilian Journal of Veterinary Research and Animal Science, 45, 354-361.

Cunningham, J. (2011). Tratado de fisiologia veterinária. Guanabara Koogan, Rio de Janeiro.

Dukes, H. H., Reece, W. O., Figueiredo, C., Vanzellotti, I. R. \& Zanon, R. F. (2006). Fisiologia dos animais domésticos. Guanabara Koogan.

Duncan, J. \& Prasse, K. 1982. Patologia clínica veterinária. UFSM, Santa Maria.

Fraser, C. M., Bergeron, J. A., Mays, A. \& Aiello, S. A. 1996. Manual Merck de Veterinária: um manual de diagnóstico, tratamento, prevenção e controle de doenças para o veterinário. Roca.

Galindo, R. C. G. (2011). Eritrograma de bovinos da raça Holandesa criados na Mesorregião Metropolitana do Recife: influência dos fatores sexuais e etário. Medicina Veterinária, $3,1-6$.

Guyton, A. C. \& Hall, J. E. (2006). Tratado de fisiologia médica. Elsevier Brasil.

Hoffbrand, A. V. \& Moss, P. A. (2013). Fundamentos em hematologia. Artmed, Porto Alegre.

Kaneko, J. J., Harvey, J. W. \& Bruss, M. L. (2008). Clinical biochemistry of domestic animals. Academic press, New York.

Lima, A. O., Soares, J. B., Greco, J. B., Galizzi, J. \& Cançado, J. R. (1992). Métodos de laboratório aplicados à clínica: técnica $e$ interpretaçäo. Guanabara Koogan, Rio e Janeiro.

Lopes, S. T. A., Biondo, A. W. \& Santos, A. P. (2007). Manual de patologia clínica 
veterinária. Universidade Federal de Santa Maria, Santa maria.

Lorenzi, T. F. (1992). Manual de hematologia: propedêutica e clínica. Guanabara - Koogan, Rio de Janeiro.

Melo, M. R., Purini, M. C., Cançado, R. D., Kooro, F. \& Chiattone, C. S. (2002). Uso de índices hematimétricos no diagnóstico diferencial de anemias microcíticas: Uma abordagem a ser adotada? Revista da Associação de Medicina Brasileira, 48, 222-4.

Núñez, O. L. \& Bouda, J. (2007). Patología Clínica Veterinaria, Mexico: FMVZ-UNAM.

Rebhun, W. C. \& Oliveira, P. M. A. (2000). Doenças do gado leiteiro. Roca, São Paulo.

Reece, W. O. (2006). Função renal nos mamíferos. In: Dukes, S. (ed.) Veterinary Medicine: a textbook of the diseases of cattle, horses, sheep, pigs and goats. Guanabara Koogan, Rio de Janeiro.

Reece, W. O. (2008). Anatomia funcional $e$ fisiologia dos animais domésticos. Editora Roca, São Paulo.

Reece, W. O. \& Penteado Júnior, N. (1996). Fisiologia de animais domésticos. Roca, São Paulo.
Silva, J. J., Carvalho, D. M. G. d., Gomes, R. A. B. \& Rodrigues, A. B. C. (2012a). Produção de leite de animais criados em pastos no Brasil. Veterinária e Zootecnia, 17, 26-36.

Silva, Z. F., Andrade, A. C., Junior, F. d. A. B., Sousa, R. S. \& Loiola, J. M. L. (2012b). Características do sistema de produção de leite da Microrregião de Imperatriz, no Estado do Maranhão. Revista de Ciências Agrárias, 55, 92-97.

Wattiaux, M. A. (1995). Mastitis: The disease and its transmission. Babcock Institute for International Dairy Research and Development, Wisconsin.

Recebido em Março 6, 2016

Aceito em Abril 12, 2016

License information: This is an open-access article distributed under the terms of the Creative Commons Attribution License, which permits unrestricted use, distribution, and reproduction in any medium, provided the original work is properly cited 